\title{
Invariant NKT cells produce IL-17 through IL-23-dependent and -independent pathways with potential modulation of Th17 response in collagen-induced arthritis
}

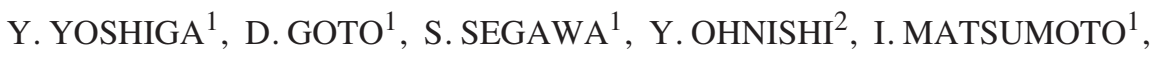

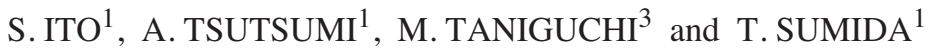 \\ ${ }^{1}$ Division of Clinical Immunology, Major of Advanced Biomedical Applications, Graduate School of Comprehensive \\ Human Sciences, University of Tsukuba, Tsukuba; ${ }^{2}$ Mitsubishi Chemical Safety Institute Ltd, Ibaraki; \\ ${ }^{3}$ Riken Research Center for Allergy and Immunology, Yokohama, Japan
}

Received March 11,2008; Accepted April 29, 2008

DOI: 10.3892/ijmm_00000032

\begin{abstract}
Invariant natural killer T (iNKT) cells play a protective role in the development of certain autoimmune diseases. However, their precise role in the pathogenesis of autoimmune arthritis remains unclear. In this study, we examined the possible contribution of iNKT cells in collageninduced arthritis (CIA) by using iNKT cell-deficient mice $\left(\mathrm{J} \alpha 281^{-/}\right.$mice). CIA in these mice was markedly suppressed and interleukin (IL)-17 production was reduced in a native type II collagen (CII)-specific T cell response. Draining lymph nodes of CII-immunized $\mathrm{J}_{\alpha} 281^{-/}$mice contained a significantly low number of IL-17-producing $\mathrm{T}$ helper cells. To determine whether iNKT cells produce IL-17, we measured IL-17 by enzyme-linked immunosorbent assay in iNKT cells stimulated with the ligand, $\alpha$-galactosylceramide ( $\alpha$-GalCer). Notably, splenocytes from $\mathrm{J} \alpha 281^{-/-}$mice stimulated in this way were negative for IL-17, whereas those from C57BL/6 mice produced IL-17. Immunostaining for IL-17 in iNKT cells confirmed intracellular staining of the protein. RT-PCR analysis showed that iNKT cells expressed retinoidrelated orphan receptor $\gamma \mathrm{T}$ and IL-23 receptor. Moreover, cell sorting demonstrated that NK1.1- iNKT cells were the main producers of IL-17 compared with NK1.1+ iNKT cells. IL-17 production by iNKT cells was induced by IL-23-dependent and -independent pathways, since iNKT produced IL-17 when stimulated with either IL-23 or $\alpha$-GalCer alone. Our findings indicate that iNKT cells are producers and activators of IL-17
\end{abstract}

Correspondence to: Dr Takayuki Sumida, Division of Clinical Immunology, Major of Advanced Biomedical Applications, Graduate School of Comprehensive Human Sciences, University of Tsukuba, 1-1-1 Tennodai, Tsukuba City, Ibaraki 305-8575, Japan

E-mail: tsumida@md.tsukuba.ac.jp

Key words: natural killer T cells, interleukin-17, collagen-induced arthritis, interleukin-23, T helper 17 cells via IL-23- dependent and -independent pathways, suggesting that they are key cells in the pathogenesis of CIA through IL-17.

\section{Introduction}

Natural killer T (NKT) cells are a subset of T lymphocytes that express NK-cell markers, such as NK1.1 in mice. The majority of NKT cells express an invariant $\mathrm{T}$ cell receptor (TCR) encoded by V $\alpha 14 \mathrm{~J} \alpha 281$ associated with highly skewed sets of Vßs, mainly Vß8.2 in mice, and they are therefore called invariant NKT (iNKT) cells. The receptor recognizes glycolipid antigen presented by CD1d, a nonclassical antigen-presenting molecule $(1,2)$. TCR stimulation induces iNKT cells to rapidly secrete large amounts of pro- and antiinflammatory cytokines, such as interleukin (IL)-4 and interferon (IFN) $-\gamma(3)$. iNKT cells are therefore known as immune regulators.

Deficiency of iNKT cells is associated with various autoimmune diseases (4-7). In animal models, iNKT cells suppress the development and progression of diabetes mellitus (8), experimental autoimmune encephalitis (EAE) (9), and systemic lupus erythematosus (10). These cells also act as effector cells in autoimmune arthritis by promoting $\mathrm{T}$ helper (Th) 1-type immune responses, inducing the production of autoantibodies, and suppressing the production of transforming growth factor (TGF)-B (11-14). The evidence thus suggests a dual function for iNKT cells in autoimmunity.

Rheumatoid arthritis (RA) is an autoimmune disorder characterized by chronic inflammation of the synovial tissues in multiple joints leading to joint destruction (15). Although the etiopathogenesis of RA remains unclear, pro-inflammatory cytokines including tumor necrosis factor (TNF)- $\alpha$, IL- $1 \beta$, and IL-6 play a major role in this process (16). It is generally accepted that IFN- $\gamma$-producing Th1 cells play a pathogenic role in the development of autoimmune diseases. In addition, IL-17 from $\mathrm{CD}^{+}{ }^{+}$effector $\mathrm{T}$ cells, but not IFN- $\gamma$, was recently implicated in the pathogenesis of EAE and collagen-induced arthritis (CIA) $(17,18)$.

IL-17 is a T cell-derived cytokine associated with a variety of autoimmune diseases. The trigger for IL-17 release 
has not been fully elucidated, but IL-23 is known to promote the production of IL-17 (19). Specifically, differentiated Th17 cells express IL-23 receptor (IL-23R) as well as orphan nuclear receptor retinoid-related orphan receptor (ROR) $\gamma \mathrm{T}$ $(20,21)$. Furthermore, IL-23-dependent IL-17-producing $\mathrm{CD}^{+}{ }^{+}$effector $\mathrm{T}$ cells, which develop via a lineage distinct from Th1 and Th2 cells, play a pathogenic role in EAE and CIA $(17,18,22)$. IL-17 is a potent inducer of various cytokines such as TNF- $\alpha$, IL-1, and receptor activator of NF- $\mathrm{KB}$ ligand (RANKL), and is involved in synovial inflammation, cartilage destruction, and bone erosion (23). Moreover, IL-17-deficient or -suppressed mice are resistant to the development of CIA (24-26).

The present study was designed to assess the role of iNKT cells in the development of one form of autoimmune arthritis, CIA, by using iNKT cell-deficient mice (J $\alpha 281^{-/-}$ mice). The results demonstrated that production of IL-17 was significantly reduced in iNKT deficient mice. The results also showed that iNKT cells produce IL-17 in IL-23-dependent and -independent pathways. The majority of IL-17producing iNKT cells were of the NK1.1' population. The findings implicate iNKT cells as producers and activators of IL-17, making them key players in the pathogenesis of CIA via IL-17.

\section{Materials and methods}

Mice. C57BL/6 (B6) mice were purchased from Charles River Japan Inc. (Tokyo, Japan). Ja281-knockout mice were kindly provided by Dr Masaru Taniguchi (Riken Research Center for Allergy and Immunology, Yokohama, Japan). The animals were kept under specific pathogen-free conditions and studied at 6-9 weeks of age. The Committee on Institutional Animal Care and Use at Tsukuba University approved all experimental plans.

Induction of CIA. Mice were immunized intradermally at the base of their tails with $100 \mu \mathrm{g}$ of chicken CII emulsified with an equal volume of complete Freund's adjuvant (CFA) and containing $250 \mu \mathrm{g}$ of H37Ra Mycobacterium tuberculosis (Difco, Detroit, MI). The animals were boosted by intradermal injection with the same antigen preparation on day 21. Joint swelling was monitored and scored as follows: 0, no swelling or redness, 1; swelling or redness in one joint, 2; two or more joints involved, 3; severe arthritis of the entire paw and joint. The score for each animal was the sum of the score for all four paws. The clinical score was calculated from all mice in the group.

Flow analysis and sorting of iNKT cells. Prior to antibody staining, cells were preincubated with anti-CD16/32 to block nonspecific $\mathrm{Fc} \gamma \mathrm{R}$ binding. The following antibodies were used in this study: FITC-conjugated anti-CD19 (BD Pharmingen, San Diego, CA), FITC-conjugated anti-CD4 (BD Pharmingen), FITC-conjugated anti-NK1.1 (eBioscience, San Diego, CA), PE- or APC-conjugated CD1d tetramer (PE, Medical \& Biological Laboratories Co., Nagoya, Japan; APC, Proimmune), and Per-CP-conjugated anti-CD3 (BD Pharmingen). Samples were acquired on a FACScalibur instrument (Pharmingen) and data were analyzed with FlowJo software.
Intracellular cytokine staining. Standard intracellular cytokine staining was performed as described previously (BD Bioscience, San Jose, CA). Cells were first stained for a cell surface marker, then fixed and permeabilized with Cytofix/ Cytoperm solution (Pharmingen), before further immunostaining with PE-conjugated anti-IL-17 (Pharmingen) or FITC-conjugated anti-IFN- $\gamma$ (eBioscience), FITC-conjugated anti-IL-4 (eBioscience), PE-conjugated Isotype Rat IgG (Pharmingen), and FITC-conjugated Isotype Rat IgG (eBioscience).

Measurement of ex vivo CII-specific T cell response. B6 and $\mathrm{J} \alpha 281^{-/}$mice were immunized intradermally with $100 \mu \mathrm{g}$ chicken CII emulsified in CFA containing $250 \mu \mathrm{g}$ of inactivated M. tuberculosis H37Ra. At 10 days after CII/CFA immunization, draining lymph node (DLN) cells were restimulated in triplicate with $100 \mu \mathrm{g} / \mathrm{ml}$ chicken CII for $72 \mathrm{~h}$. IL-17 concentrations in the culture supernatant were measured by enzyme-linked immunosorbent assay (ELISA). Analysis of cytokine production by DLN cells was performed by first isolating these cells from B6 and $\mathrm{J} \alpha 281^{-1-}$ mice at 10 days after CII immunization, and then their culture $\left(1 \times 10^{6}\right.$ cells $\left./ \mathrm{ml}\right)$ for $72 \mathrm{~h}$ in 96-well plates with $100 \mu \mathrm{g} / \mathrm{ml}$ of CII. Golgistop (BD Pharmingen) was added for the final $6 \mathrm{~h}$ of culture before cytokine staining to enhance intracellular protein accumulation.

Activation of iNKT cells in vitro. Splenocytes from B6 and $\mathrm{J} \alpha 281^{-/}$mice were collected and stimulated with or without $100 \mathrm{ng} / \mathrm{ml}$ or sequential amounts $(0,1,10,100,1000 \mathrm{ng} / \mathrm{ml})$ of $\alpha$-galactosylceramide ( $\alpha$-GalCer), for $72 \mathrm{~h}$ in $96-w e l l$ round-bottom plates. Cytokine concentrations in the culture supernatants were measured by ELISA. The cells were used for intracellular cytokine staining. In experiments shown in Fig. 4, sorted total iNKT cells, NK1.1+iNKT cells or NK1.1 iNKT cells $\left(2 \times 10^{3}\right.$ cells/well $)$ were cultured with mitomycinC-treated CD11 $\mathrm{c}^{+}$cells $\left(2 \times 10^{3}\right.$ cells/well), which were selected by MACS CD11c-beads from splenocytes as antigen-producing cells (APC), in the presence or absence of $10 \mathrm{ng} / \mathrm{ml}$ IL-23 (eBioscience) and/or $10 \mathrm{ng} / \mathrm{ml} \alpha$-GalCer (Kirin Brewery Co.). For neutralization of IL-23, splenocytes were stimulated with $10 \mathrm{ng} / \mathrm{ml} \alpha$-GalCer or $100 \mathrm{pg} / \mathrm{ml}$ rIL-23 (eBiosciences) plus $100 \mathrm{IU} / \mathrm{ml} \mathrm{IL-2} \mathrm{for} 72 \mathrm{~h}$ in the presence of sequential amounts of anti-IL-23 antibody $(0,0.3,1,3 \mu \mathrm{g} / \mathrm{ml}$; eBiosciences) or isotype-matched control IgG (eBiosciences).

$R T-P C R$. Total RNA was extracted from purified iNKT cells, B cells and Th17 cells, and was reverse transcribed into cDNA using RevertAid ${ }^{\mathrm{TM}}$ First-strand cDNA Synthesis kit (Fermentas, Burlington, ONT, Canada) according to the protocol supplied by the manufacturer. iNKT cells (CD1d tetramer ${ }^{+} \mathrm{CD} 3{ }^{+} \mathrm{CD} 19$ - cells) were sorted from naive or $\alpha$-GalCer stimulated splenocytes. B cells were purified from $\alpha$-GalCer-stimulated splenocytes using anti-CD19 magnetic microbeads as recommended by the manufacturer (Miltenyi Biotec, Bergisch Gladbach, Germany). For induction of Th17 cells, MACS-purified CD4 ${ }^{+} \mathrm{T}$ cells were cultured with $20 \mathrm{ng} / \mathrm{ml}$ IL-6 (eBioscience) and $5 \mathrm{ng} / \mathrm{ml}$ TGF- 3 (R\&D Systems, Minneapolis, MN) in 96-well plates containing plate bound anti-CD3 $(5 \mu \mathrm{g} / \mathrm{ml})$ and soluble anti-CD28 $(1 \mu \mathrm{g} / \mathrm{ml})$ 
for 3 days. The following primers were used for PCR: GAPDH: forward AACTTTGGCATTGTGGAAGG, reverse ACACATTGGGGGTAGGAACA; IL-17: forward TCCAG AAGGCCCTCAGACTA, reverse AGCATCTTCTCGAC CCTGAA; and ROR $\gamma$ T: forward TGCAAGACTCATC GACAAGG, reverse AGGGGATTCAACATCAGTGC. The results were normalized with GAPDH expression.

Statistical analysis. The Mann-Whitney U Test was used for comparisons of clinical score of arthritis and ex vivo $\mathrm{T}$ cell response. The Student's t-test was used for in vitro iNKT cell response. $\mathrm{P}<0.05$ denoted the presence of a statistically significant difference.

\section{Results}

iNKT cells promote joint inflammation. iNKT cells act as regulatory cells in some autoimmune diseases. However, in the development of autoimmune arthritis, an effector function has been assigned to these cells (11-14). To confirm the specific role of iNKT cells in the development of collageninduced arthritis (CIA), we examined the incidence and severity of arthritis in iNKT cell-deficient $\mathrm{J} \alpha 281^{-/}$mice and B6 controls. The incidence of arthritis and disease severity in mice lacking iNKT cells was markedly lower than in B6 mice (Fig. 1A and B). These results suggest that iNKT cells promote joint inflammation in the development of CIA.

iNKT cells enhance IL-17 production. We examined whether the presence or absence of iNKT cells altered the T cell response to type II collagen (CII). We isolated the draining lymph node (DLN) cells from B6 mice and iNKT celldeficient mice 10 days after the first immunization with $\mathrm{CII}$, and then further stimulated the DLN cells with CII in vitro. There was significantly less IL-17 in the culture supernatant of $\mathrm{J}_{\alpha 2} 281^{-/}$cells than in cultures of B6 DLN cells. However, the concentrations of IL-4, IL-10, and IFN- $\gamma$ did not differ between these mice (Fig. 2A). It was suggested that IL-17producing $\mathrm{CD}^{+} \mathrm{T}$ cells (Th17 cells) play a crucial role in the generation of autoimmune diseases $(17,18,20)$. To determine whether iNKT cells accelerate IL-17 production by Th17 cells in CIA, we measured cytokine production by $\mathrm{CD} 4^{+} \mathrm{T}$ cells in DLN. The percentage of IL-17-producing CD4+ $\mathrm{T}$ cells (Th17 cells) was lower in $\mathrm{J} \alpha 281^{-/}$mice than in $\mathrm{B} 6$ mice (Fig. 2B, $\mathrm{P}<0.01$ ), suggesting that iNKT cells enhance Th17 cell activation in the development of CIA.

iNKT cells synthesize and secrete IL-17. We hypothesized that iNKT cells directly produced IL-17 and that IL-17 promoted the pathogenesis of CIA. We stimulated iNKT cells obtained from naive B6 and iNKT cell-deficient mice with the iNKT cell ligand, $\alpha$-GalCer. Isolated splenocytes were further stimulated with $\alpha$-GalCer, and the amount of IL-17 in the culture supernatant was assayed. iNKT cells from B6 mice stimulated with $\alpha$-GalCer showed dose-dependent IL-17 production, while iNKT cell-deficient mice were negative for IL-17 (Fig. 3A and B). The $\alpha$-GalCer-stimulated splenocytes were then immunostained to localize IL-17 and identify the IL-17-producing cells (Fig. 3C). Notably, a small population of IL-17+ iNKT cells was observed in B6 mice, but none were
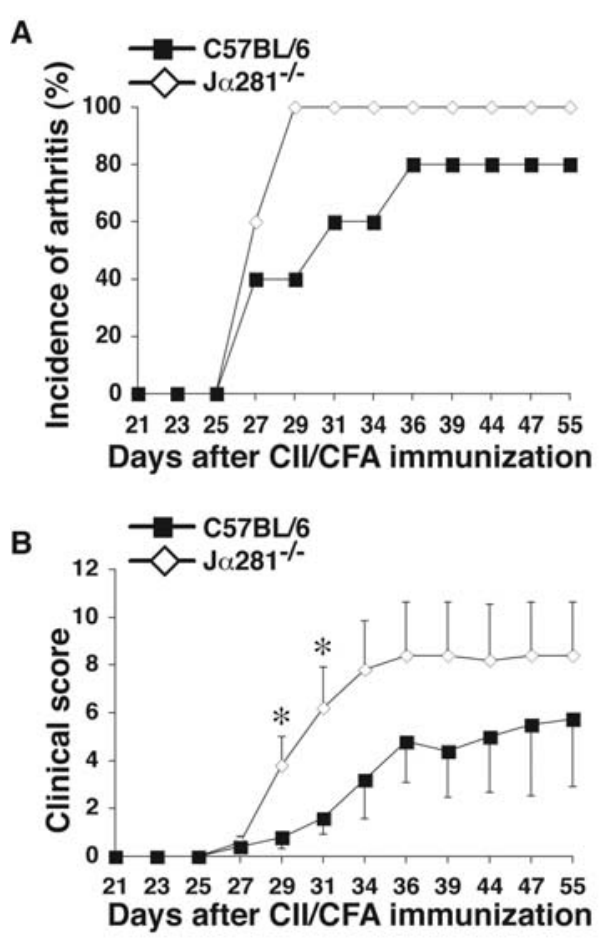

Figure 1. iNKT cells promote joint inflammation in collagen-induced arthritis (CIA). Incidence of arthritis (A) and clinical scores (B) in $\mathrm{J}_{\alpha 2} 281^{-/-}$ (solid symbols) and B6 (open symbols) mice. Data are representative of two experiments. Error bars, SEM; $\mathrm{n}=5$ mice per group. ${ }^{*} \mathrm{P}<0.05$.
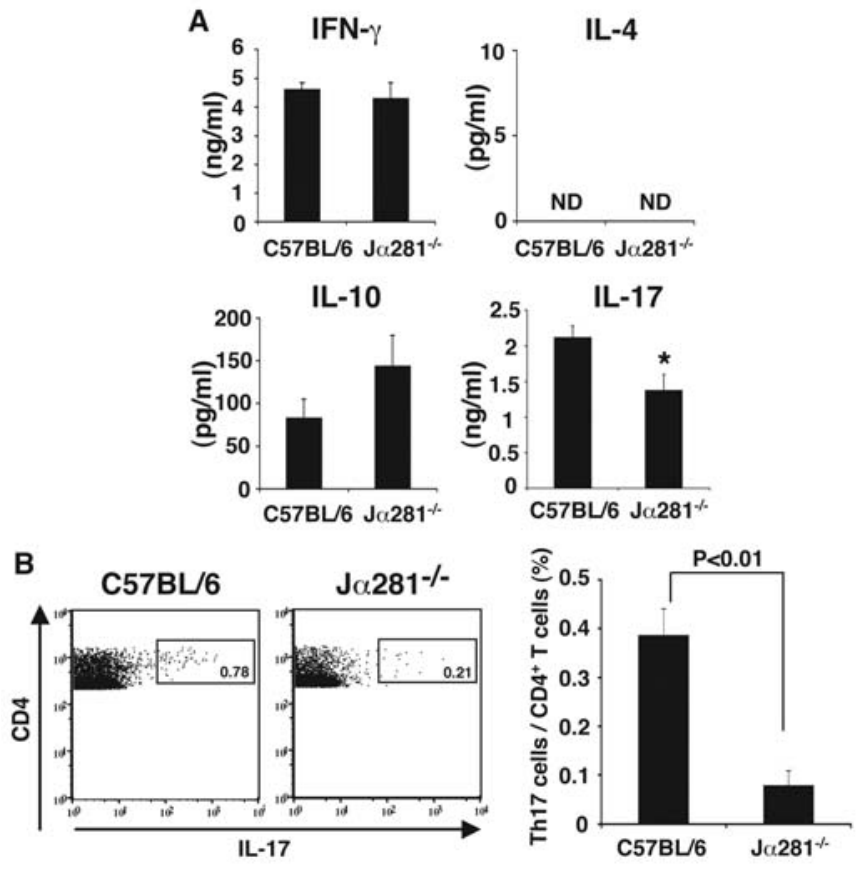

Figure 2. Low proportion of Th17 cells in draining lymph node (DLN) cells from type II collagen (CII)-immunized J $\alpha 281^{-/-}$mice. At 10 days after CII/ complete Freund's adjuvant (CFA) immunization, DLN cells were restimulated with CII for 72 h. (A) IFN- $\gamma$, IL-4, IL-10, and IL-17 concentrations in the culture supernatant were measured by ELISA. (B) Left: representative flow cytometry demonstrating IL-17 expression in $\mathrm{CD}^{-/-} \mathrm{T}$ cells $\left(\mathrm{CD} 4^{+} \mathrm{CD}^{+}\right.$ population) of DLN cells from B6 and $\mathrm{J} \alpha 281^{-/-}$mice. Right: proportion of IL-17-producing CD4 ${ }^{+} \mathrm{T}$ cells among DLN cells from B6 and $\mathrm{J} \cdot 281^{-/-}$mice expressed as a percentage of total $\mathrm{CD}^{+} \mathrm{T}$ cells. Data are representative of at least two experiments with similar results. Error bars, SEM; $n=5$ mice per group. ${ }^{*} \mathrm{P}<0.05$. ND, not detected. 

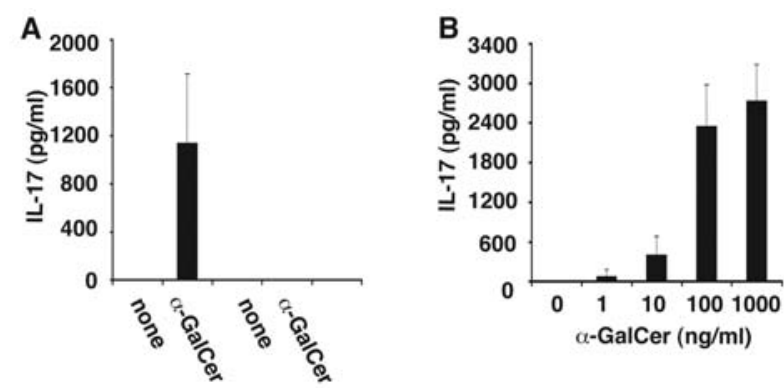

$\overline{\mathrm{C57BL} / 6} \overline{\mathrm{J} \alpha 281^{*}}$

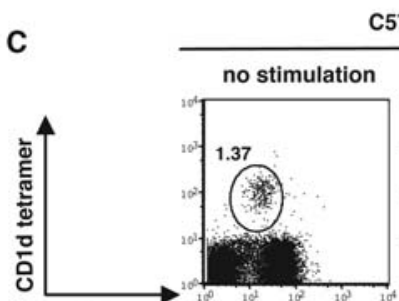

C57BL/6
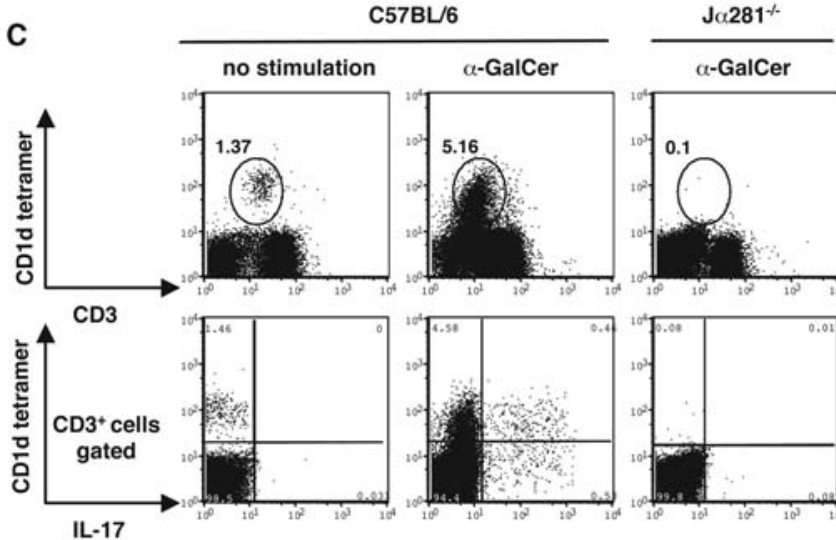

D
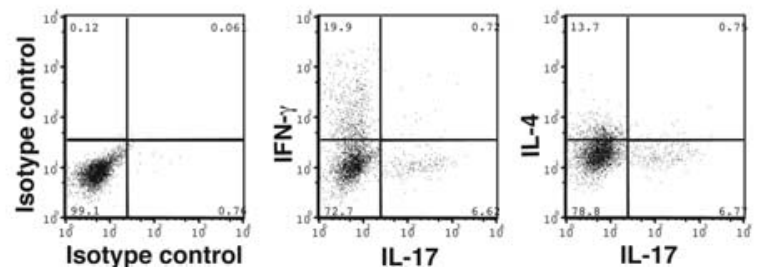

Figure 3. Glycolipid antigen-stimulated iNKT cells synthesize and secrete IL-17. (A) Splenocytes from naive B6 and $\mathrm{J} \alpha 281^{-/-}$mice were collected and stimulated with or without $\alpha$-GalCer for $72 \mathrm{~h}$ in triplicate. IL-17 levels in the supernatant were measured by ELISA. (B) Splenocytes from B6 mice were stimulated with various concentrations of $\alpha$-GalCer $(0,1,10,100$, $1000 \mathrm{ng} / \mathrm{ml})$, and IL-17 levels in the supernatants were then measured by ELISA. (C) Top panels: population of splenocytes from B6 or $\mathrm{J} \alpha 281^{-/-}$mice stimulated with or without $\alpha$-GalCer for $72 \mathrm{~h}$. The CD19-CD1d tetramer ${ }^{+}$ $\mathrm{CD}^{+}$cells were counted as iNKT cells. Bottom panels: IL-17 production by splenocytes from B6 or $\mathrm{J} \alpha 281^{-/}$mice stimulated with or without $\alpha$-GalCer for $72 \mathrm{~h}$. CD19-CD3 ${ }^{+}$cells were gated and $\mathrm{IL}-17^{+} \mathrm{CD} 1 \mathrm{~d}$ tetramer ${ }^{+}$cells were estimated as IL-17-producing iNKT cells. (D) Intracellular IL-17, IFN- $\gamma$ and IL-4 staining was performed after in vitro stimulation of splenocytes at $72 \mathrm{~h}$ and analyzed among gated iNKT cells $\left(\mathrm{CD} 1 \mathrm{~d}\right.$ tetramer $\left.{ }^{+} \mathrm{CD} 3^{+}\right)$by flow cytometry. Data are representative of three independent experiments.

evident in the $\mathrm{J} \alpha 281^{-/-}$mice (Fig. 3C), suggesting that iNKT cells themselves produce IL-17. Moreover, IL-17-producing iNKT cells did not produce IFN- $\gamma$ or IL-4 (Fig. 3D). The above experiments indicate the presence of IL-17-producing iNKT cells, although there is no evidence that IL-17-producing iNKT cells are specifically Th17 activators.

NK1.1-iNKT cell-mediated IL-17 production is dependent on and independent of IL-23. IL-23 is a heterodimeric protein consisting of common IL-12p40 and IL-23p19 and is essential for maintenance of Th17 cells $(18,19)$. To establish whether the same effect was seen in iNKT cells, we analyzed the expression of IL-23R as well as ROR $\gamma \mathrm{T}$ by RT-PCR. As shown in Fig. 4A, naive and activated iNKT cells expressed

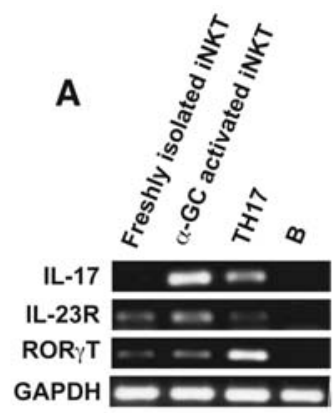

B

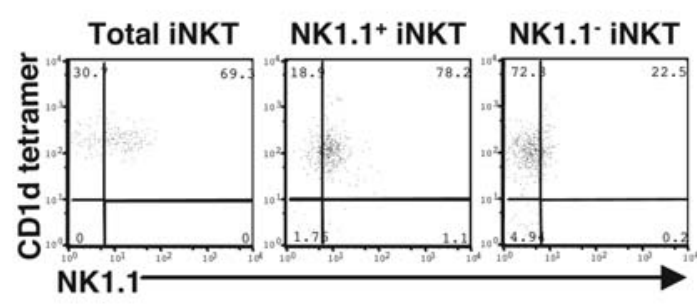

C

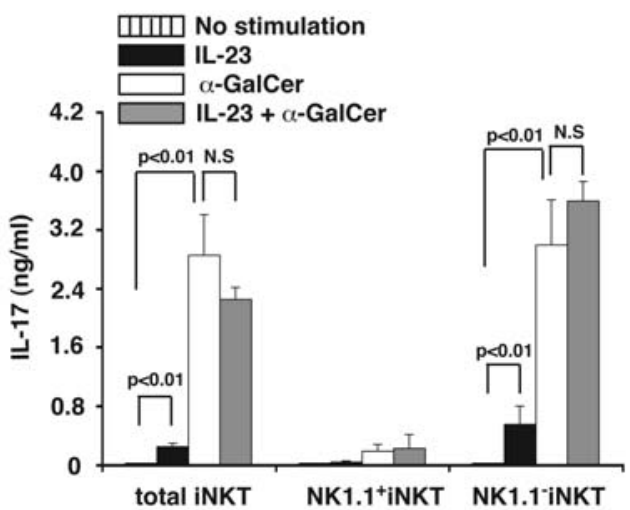

D

IL-23-induced IL-17

$\alpha$-GalCer-induced IL-17
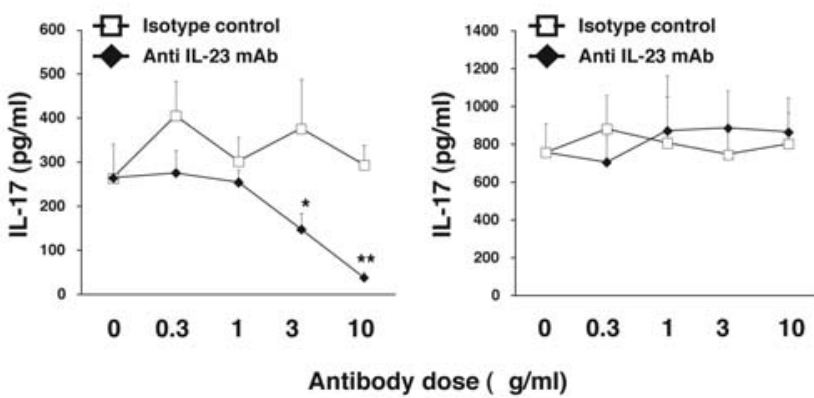

Figure 4. Phenotype of IL-17-producing iNKT cells. (A) IL-17, ROR $\gamma$ T and IL-23R expression in purified iNKT cells was determined by using RT-PCR. Lane 1, iNKT cells from naive splenocytes; Lane 2, iNKT cells from $\alpha$-GalCer-stimulated splenocytes; Lane 3, Th17 cells; Lane 4, B cells from $\alpha$-GalCer-stimulated splenocytes. (B) Representative FACS profiles of sorted total iNKT cells, NK1.1 ${ }^{+}$iNKT cells and NK1.1 ${ }^{-}$iNKT cells. The purity of iNKT cells in this experiment was $>95 \%$ (total iNKT), $>78 \%\left(\mathrm{NK} 1.1^{+} \mathrm{iNKT}\right)$ and $>72 \%\left(\mathrm{NK} 1.1^{-} \mathrm{iNKT}\right)$. (C) Sorted total iNKT cells, NK1.1+iNKT cells, and NK1.1-iNKT cells were co-cultured with mitomycin-C-treated CD11c as APC and stimulated with IL-23, $\alpha$-GalCer, or IL-23 plus $\alpha$-GalCer. IL-17 was measured in the supernatants after $72 \mathrm{~h}$. No IL-17 was detected in unstimulated total iNKT, NK1.1+iNKT, and NK1.1+iNKT cells. (D) Splenocytes were stimulated with $\alpha$-GalCer or rIL23 plus rIL-2 in the presence of anti-IL-23 mAb or control Ig. IL-17 was measured in the supernatants after $72 \mathrm{~h} .{ }^{*} \mathrm{P}<0.01 ;{ }^{* *} \mathrm{P}<0.01$. Data are representative of three independent experiments. N.S, not significant. 


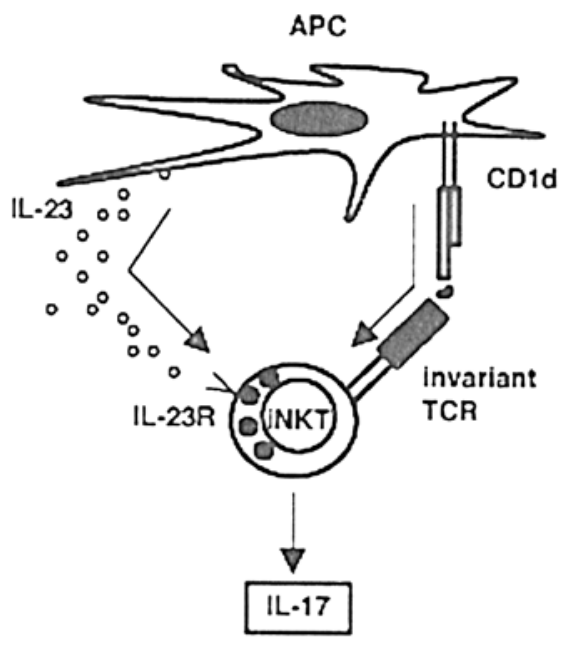

Figure 5. IL-17 production by iNKT cells is regulated through two distinct pathways, IL-23-dependent and IL-23-independent. Left: IL-23-dependent IL-17 production by iNKT cells through IL-23R. Right: IL-23-independent IL-17 production by iNKT cells through invariant T cell receptor (TCR). $\mathrm{APC}$, antigen presenting cells.

IL-23R and ROR $\gamma \mathrm{T}$ similar to Th17 cells. Notably, IL-17 expression was detected in activated iNKT cells and not in naive iNKT cells, suggesting that IL-17 gene was inducible in the iNKT cell activation. Recently, Michel et al (27) reported that only NK1.1-iNKT cells could produce IL-17. To examine whether the production of IL-17 by iNKT cells was dependent or independent of IL-23, splenocytes from naive B6 mice were sorted into either NK1.1-iNKT cells, NK1.1 ${ }^{+}$iNKT cells, and total iNKT cells (Fig. 4B), and then each group was co-cultured with $\mathrm{CD} 11^{+}$dendritic cells (DC) as antigen-producing cells in the presence or absence of IL-23 and $\alpha$-GalCer. Fig. 4C clearly shows that total iNKT cells produced IL-17 by either IL-23 or $\alpha$-GalCer alone, indicating that iNKT cells can generate IL-17 through IL-23-dependent and IL-23-independent pathways. The effect of $\alpha$-GalCer on IL-17 production was not through IL-23 production, as no IL-23 was found in the culture supernatant from iNKT cells stimulated with $\alpha$-GalCer (data not shown) and antiIL-23 mAb did not block $\alpha$-GalCer-induced IL-17 production (Fig. 4D). No additional effect for IL-23 and $\alpha$-GalCer stimulation was observed (Fig. 4C). These results suggest that NK1.1-iNKT cells produced IL-17 through IL-23dependent and -independent pathways.

\section{Discussion}

iNKT cells act as regulatory cells in certain autoimmune diseases. However, in the development of autoimmune arthritis, an effector function has been assigned to these cells (11-14). Both the severity of arthritis and autoantibody production was reduced in iNKT cell-deficient mice with CIA $(11,12)$. In addition, the $\mathrm{T}$ cell response to autoantigens shifted from Th1 to Th2 in these mice (11). Furthermore, in antibody-induced arthritis, iNKT cells suppressed TGF- $\beta$ expression in joints, suggesting an effector-cell function $(13,14)$. The present results indicate that iNKT cells function as IL-17 producers and activators in autoimmune arthritis.
This is the first time that the role of iNKT cells through IL17 production in the development of CIA has been reported. Moreover, we propose two functional roles for iNKT cells in the development of CIA. The first is upregulation of IL-17 production by CII-reactive Th17 cells, while the second is direct production of IL-17 (Fig. 5).

IL-17 is a pathogenic cytokine in autoimmune diseases such as EAE and CIA, since its neutralization or deficiency reduces the severity of disease (24-26). Our study demonstrated that deficiency of iNKT cells reduced CII-reactive IL-17 production in CIA mice. These findings suggest that iNKT cells are associated with IL-17 production and that these cells play a crucial role in the development of CIA.

Previous studies showed that Th17 cells are distinct from the traditional Th1- and Th2-cell subsets, and that they are important in regulating tissue inflammation and the development of disease in several animal models of autoimmunity $(20,22,28,29)$. TGF- 3 promotes Th17-cell development in the presence of IL-6 (30-32), and IL-23 is critical for the maintenance of Th17-cell activation in chronic inflammation (20). Our study demonstrated that iNKT cells enhance IL-17 production by Th17 cells in CIA. Some reports have shown that activated iNKT cells induce maturation of DC, and thereby, enhance the antigen-specific $\mathrm{T}$ cell response $(33,34)$. In addition, Eberl et al (35) suggested that iNKT cells contribute to the maintenance and persistent stimulation of memory $\mathrm{T}$ cells through cytokine secretion. Recent reports suggested that IL-21, which activates Th17 cells (36-38), is produced by iNKT cells $(39,40)$. Thus, we speculate that iNKT cells might maintain or activate Th17 cells in CIA mice.

In this study, we clearly demonstrated that iNKT cells synthesize and release IL-17 in addition to accelerating IL-17 production by Th17 cells. Moreover, the main cell population of IL-17-producing iNKT cells is NK1.1- cells. In recent study, Michel et al (27) reported a similar finding in relation to IL-17-producing iNKT cells. Although the function of NK1.1 in IL-17 production is not clear at present, NK1.1 may be a key regulatory molecule in IL-17 production by iNKT cells. In our study, we demonstrated that iNKT cells expressed ROR $\gamma \mathrm{T}$ as well as Th17 cells, indicating that ROR $\gamma \mathrm{T}$ might also be involved in IL-17 production by iNKT cells as well as Th17 cells.

Several IL-17-producing cells have been identified, such as CD4 T cells (Th17) and $\gamma \delta \mathrm{T}$ cells, with IL-17 production dependent on IL-23. In contrast, Mangan et al (32) detected IL-17 in IL-23-deficient mice and Liu et al (41) showed short-term production of IL-17 induced by TCR stimulation in the absence of IL-23. Thus, IL-17 might be regulated in an IL-23-dependent or -independent manner. In our system, iNKT cells produced IL-17 not only by IL-23 but also by $\alpha$-GalCer alone. Therefore, IL-17 production by iNKT cells is regulated by two distinct pathways (Fig. 5).

In conclusion, we demonstrated that iNKT cells can produce IL-17 by themselves and enhance Th17 cell activity, thus playing a significant role in the development of collageninduced arthritis (CIA). Moreover, we also showed that iNKT cells (mainly the NK1.1- cell population) can secrete IL-17 through two stimulation pathways, the IL-23-IL-23R pathway and the glycolipid antigen-TCR pathway. 


\section{Acknowledgements}

We thank Dr F.G. Issa for a critical reading of the manuscript. This study was supported in part by the Japanese Ministry of Science and Culture, and the Japanese Ministry of Health, Labour and Welfare.

\section{References}

1. Kronenberg $\mathrm{M}$ and Gapin L: The unconventional lifestyle of NKT cells. Nat Rev Immunol 2: 557-568, 2002.

2. Van Kaer L: Alpha-galactosylceramide therapy for autoimmune diseases: prospects and obstacles. Nat Rev Immunol 5: 31-42, 2005.

3. Chen $\mathrm{H}$ and Paul WE: Cultured NK1.1 ${ }^{+} \mathrm{CD} 4^{+} \mathrm{T}$ cells produce large amounts of IL-4 and IFN- $\gamma$ upon activation by anti-CD3 or CD1. J Immunol 159: 2240-2249, 1997.

4. Sumida T, Sakamoto A, Murata $\mathrm{H}$, et al: Selective reduction of $\mathrm{T}$ cells bearing invariant $\mathrm{V} \alpha 24 \alpha \mathrm{Q}$ antigen receptor in patients with systemic sclerosis. J Exp Med 182: 1163-1168, 1995.

5. Sumida T, Maeda T, Taniguchi M, et al: TCRAV24 gene expression in double negative $\mathrm{T}$ cells in systemic lupus erythematosus. Lupus 7: 565-568, 1998 .

6. Maeda T, Keino H, Asahara H, et al: Decreased TCR AV24AJ18 ${ }^{+}$double negative $\mathrm{T}$ cells in rheumatoid synovium. Rheumatology 38: 186-188, 1999.

7. Kojo S, Adachi Y, Keino $\mathrm{H}$, et al: Dysfunction of $\mathrm{T}$ cell receptor AV24AJ18+, BV11+ double-negative regulatory natural killer T cells in autoimmune diseases. Arthritis Rheum 44: 1127-1138, 2001

8. Hong S, Wilson MT, Serizawa I, et al: The natural killer T-cell ligand $\alpha$-galactosylceramide prevents autoimmune diabetes in NOD mice. Nat Med 7: 1052-1056, 2001

9. Singh AK, Wilson MT, Hong S, et al: Natural killer T cell activation protects mice against experimental autoimmune encephalomyelitis. J Exp Med 194: 1801-1811, 2001.

10. Yang JQ, Singh AK, Wilson MT, et al: Immunoregulatory role of CD1d in the hydrocarbon oil-induced model of lupus nephritis. J Immunol 171: 2142-2153, 2003

11. Chiba A, Kaieda S, Oki S, et al: The involvement of $\mathrm{V} \alpha 14$ natural killer $\mathrm{T}$ cells in the pathogenesis of arthritis in murine models. Arthritis Rheum 52: 1941-1948, 2005.

12. Ohnishi Y, Tsutsumi A, Goto D, et al: TCR Valpha14 natural killer $\mathrm{T}$ cells function as effector $\mathrm{T}$ cells in mice with collageninduced arthritis. Clin Exp Immunol 141: 47-53, 2005.

13. Kim HY, Kim HJ, Min HS, et al: NKT cells promote antibodyinduced joint inflammation by suppressing transforming growth factor B1 production. J Exp Med 201: 41-47, 2005.

14. Kim HY, Kim S and Chung DH: FcgammaRIII engagement provides activating signals to NKT cells in antibody-induced joint inflammation. J Clin Invest 116: 2484-2492, 2006.

15. Harris ED Jr: Rheumatoid arthritis. Pathophysiology and implications for therapy. N Engl J Med 322: 1277-1289, 1990.

16. Luross JA and Williams NA: The genetic and immunopathological processes underlying collagen-induced arthritis. Immunology 103: 407-416, 2001.

17. Murphy CA, Langrish CL, Chen Y, et al: Divergent pro- and antiinflammatory roles for IL-23 and IL-12 in joint autoimmune inflammation. J Exp Med 198: 1951-1957, 2003.

18. Langrish CL, Chen Y, Blumenschein WM, et al: IL-23 drives a pathogenic $\mathrm{T}$ cell population that induces autoimmune inflammation. J Exp Med 201: 233-240, 2005.

19. Aggarwal S, Ghilardi N, Xie MH, et al: Interleukin-23 promotes a distinct CD4 $\mathrm{T}$ cell activation state characterized by the production of interleukin-17. J Biol Chem 278: 1910-1914, 2003

20. Kikly K, Liu L, Na S and Sedgwick JD: The IL-23/Th(17) axis: therapeutic targets for autoimmune inflammation. Curr Opin Immunol 18: 670-675, 2006.

21. Ivanov II, McKenzie BS, Zhou L, et al: The orphan nuclear receptor ROR gamma directs the differentiation program of proinflammatory $\mathrm{IL}-17^{+} \mathrm{T}$ helper cells. Cell 126: 1121-1133, 2006.
22. Harrington LE, Hatton RD, Mangan PR, et al: Interleukin 17 producing $\mathrm{CD}^{+}$effector $\mathrm{T}$ cells develop via a lineage distinct from the T helper type 1 and 2 lineages. Nat Immunol 6: 1123-1132, 2005

23. Stamp LK, James MJ and Cleland LG: Interleukin-17: the missing link between T-cell accumulation and effector cell actions in rheumatoid arthritis? Immunol Cell Biol 82: 1-9, 2004.

24. Nakae S, Nambu A, Sudo K, et al: Suppression of immune induction of collagen-induced arthritis in IL-17-deficient mice. J Immunol 171: 6173-6177, 2003.

25. Lubberts E, Joosten LA, Oppers B, et al: IL-1-independent role of IL-17 in synovial inflammation and joint destruction during collagen-induced arthritis. J Immunol 167: 1004-1013, 2001.

26. Lubberts E, Koenders MI, Oppers-Walgreen B, et al: Treatment with a neutralizing anti-murine interleukin-17 antibody after the onset of collagen-induced arthritis reduces joint inflammation, cartilage destruction, and bone erosion. Arthritis Rheum 50: 650-659, 2004

27. Michel ML, Keller AC, Paget C, et al: Identification of an IL-17producing NK1.1(neg) iNKT cell population involved in airway neutrophilia. J Exp Med 204: 995-1001, 2007.

28. Park H, Li Z, Yang XO, et al: A distinct lineage of CD4 T cells regulates tissue inflammation by producing interleukin 17 . Nat Immunol 6: 1133-1141, 2005.

29. Yen D, Cheung J, Scheerens $\mathrm{H}$, et al: IL-23 is essential for T cell-mediated colitis and promotes inflammation via IL-17 and IL-6. J Clin Invest 116: 1310-1316, 2006.

30. Veldhoen M, Hocking RJ, Atkins CJ, et al: TGFß in the context of an inflammatory cytokine milieu supports de novo differentiation of IL-17-producing T cells. Immunity 24: 179-189, 2006

31. Bettelli E, Carrier Y, Gao W, et al: Reciprocal developmental pathways for the generation of pathogenic effector TH17 and regulatory T cells. Nature 441: 235-238, 2006.

32. Mangan PR, Harrington LE, O'Quinn DB, et al: Transforming growth factor-beta induces development of the $\mathrm{T}(\mathrm{H}) 17$ lineage. Nature 441: 231-234, 2006

33. Fujii S, Shimizu K, Smith C, et al: Activation of natural killer T cells by $\alpha$-galactosylceramide rapidly induces the full maturation of dendritic cells in vivo and thereby acts as an adjuvant for combined CD4 and CD8 T cell immunity to a coadministered protein. J Exp Med 198: 267-279, 2003.

34. Hermans IF, Silk JD, Gileadi U, et al: NKT cells enhance CD4 ${ }^{+}$ and $\mathrm{CD} 8^{+} \mathrm{T}$ cell response to soluble antigen in vivo through direct interaction with dendritic cells. J Immunol 171: 5140-5147, 2003

35. Eberl G, Brawand P, MacDonald HR: Selective bystander proliferation of memory CD4 and CD8 T cells upon NKT or T cell activation. J Immunol 165: 4305-4311, 2000.

36. Nurieva R, Yang XO, Martinez G, et al: Essential autocrine regulation by IL-21 in the generation of inflammatory T cells. Nature 448: 480-483, 2007

37. Korn T, Bettelli E, Gao W, et al: IL-21 initiates an alternative pathway to induce proinflammatory $\mathrm{T}(\mathrm{H}) 17$ cells. Nature 448 : 484-487, 2007.

38. Zhou L, Ivanov II, Spolski R, et al: IL-6 programs T(H)-17 cell differentiation by promoting sequential engagement of the IL-21 and IL-23 pathways. Nat Immunol 8: 967-974, 2007.

39. Coquet JM, Kyparissoudis K, Pellicci DG, et al: IL-21 is produced by NKT cells and modulates NKT cell activation and cytokine production. J Immunol 178: 2827-2834, 2007.

40. Harada M, Magara-Koyanagi K, Watarai H, et al: IL-21induced Bepsilon cell apoptosis mediated by natural killer T cells suppresses IgE responses. J Exp Med 203: 2929-2937, 2006

41. Liu XK, Clements JL and Gaffen SL: Signaling through the murine $\mathrm{T}$ cell receptor induces IL-17 production in the absence of costimulation, IL-23 or dendritic cells. Mol Cells 20: 339-347, 2005 